\title{
Internal Resonance and Active Vibration Control of Tracked Emergency Ambulance
}

\author{
Yan-Ying Zhao a, ${ }^{\text {, }}$, Jia Yin and Fang-Gui Yu
}

School of Aircraft Engineering, Nanchang Hangkong University, Nanchang 330063, China

ayanyingzhao@163.com

${ }^{*}$ Corresponding author

Keywords: Tracked Emergency Ambulance, Active Vibration Control, Internal Resonance

Abstract. In the present paper, the multiple scales is applied to investigate the internal resonance and vibration suppression of the system of tracked emergency ambulance. The delayed feedback control is employed to suppress the amplitude of the primary system when the 1:2 internal resonance occurs. The effect of gain and time delay on vibration suppression is investigated. The results show that it can be chose the appropriate values of gain and time delay to obtain the best performance of vibration suppression for the primary system.

\section{Introduction}

The tracked emergency ambulance is the vehicle equipped with emergency equipment, medicines and stretchers used to transport the sick and wounded ${ }^{[1]}$. In order to achieve wounded security transfer and the way to treat wounded, it is necessary to have good mobility to satisfy comfort for sick and wounded. It is important to study the vibration reduction of the tracked emergency ambulance vibrating system ${ }^{[2]}$. Yang et al. ${ }^{[3]}$ investigate the physical properties of tracked emergency ambulance, and the mechanics model is optimized. The focus of present paper is to apply the delayed feedback control to suppress the vibration of the primary system of tracked emergency ambulance. The technique of delayed feedback control vibration absorber is a new technique of vibration suppression. Delayed position feedback control applied to dynamical structures was first presented by Olgac et al. ${ }^{[4]}$ by introducing a delayed resonator. Recently, the author's research ${ }^{[5,6]}$ show that the delayed feedback control can be used to suppress the vibration of the primary system in the nonlinear system.

\section{The formulation of the Problem}

A two degree of freedom tracked emergency ambulance vibrating system is shown in Fig. 1. The governing equations of the delayed feedback control system are

$$
\mathrm{m}_{2}+\mathrm{c}_{1}\left(-\mathrm{c}_{1}\left(\mathrm{x}_{1}-\mathrm{x}_{2}\right)+\mathrm{k}_{\mathrm{n}}\left(\mathrm{x}_{1}-\mathrm{x}_{2}\right)^{2}+\rho_{1} \&(\mathrm{t}-\tau)=0\right.
$$

Fig. 1: A two degree of freedom tracked emergency ambulance vibrating system with delayed feedback control 
Here, it is defined the wounded and stretcher as primary system and the frame as isolation system. Then $\mathrm{m}_{1}$ and $\mathrm{m}_{2}$ are the mass of the primary system and isolation system, $\mathrm{k}_{1}$ and $\mathrm{k}_{2}$ are the linear spring stiffness of the primary system and isolation system, $\mathrm{k}_{1}$ is the nonlinear spring stiffness between primary system and isolation system. $c_{1}$ and $c_{2}$ are the linear damping coefficients of the primary system and isolation system respectively. $\rho_{1}$ is the linear damping feedback gain of the delayed feedback control signal, $\tau$ is the time delay, and $\&(t-\tau)=\&_{\tau} . f$ is the amplitude corresponding to the external excitation force, $\omega$ is the frequency of external excitation, $t$ is the time, and $(\cdot)=\mathrm{d}() / \mathrm{dt}$.

Eqs. (1) and (2) can be expressed as

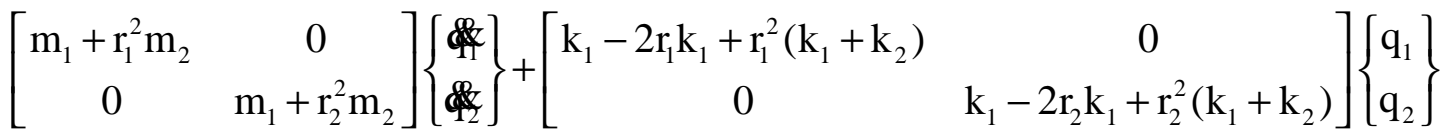

$$
\begin{aligned}
& +\varepsilon\left[\begin{array}{cc}
c_{1}-2 r_{1} c_{1}+r_{1}^{2}\left(c_{1}+c_{2}\right) & c_{1}-r_{1} c_{1}-r_{2} c_{1}+r_{1} r_{2}\left(c_{1}+c_{2}\right) \\
c_{1}-r_{1} c_{1}-r_{2} c_{1}+r_{1} r_{2}\left(c_{1}+c_{2}\right) & c_{1}-2 r_{2} c_{1}+r_{2}^{2}\left(c_{1}+c_{2}\right)
\end{array}\right]\left\{\begin{array}{c}
\& \\
\& \\
\&
\end{array}\right\} \\
& +\varepsilon\left\{\begin{array}{l}
\left(1-r_{1}\right) k_{n}\left(q_{1}+q_{2}-r_{1} q_{1}-r_{2} q_{2}\right)+\left(1-r_{1}\right) \rho_{1}\left(\&_{\tau}+q_{2 \tau}\right) \\
\left(1-r_{2}\right) k_{n}\left(q_{1}+q_{2}-r_{1} q_{1}-r_{2} q_{2}\right)+\left(1-r_{2}\right) \rho_{1}\left(\&_{\tau}+q_{2 \tau}\right)
\end{array}\right\}=\varepsilon\left\{\begin{array}{l}
r_{1} f \cos (\omega t) \\
r_{2} f \cos (\omega t)
\end{array}\right\}
\end{aligned}
$$

where $\omega_{1}$ and $\omega_{2}$ are the first and second modal frequency of the vibrating system, $r_{1}=1-\frac{m_{1}}{k_{1}} \omega_{1}^{2}$, $\mathrm{r}_{2}=1-\frac{\mathrm{m}_{1}}{\mathrm{k}_{1}} \omega_{2}{ }^{2}, \mathrm{c}_{1}=\varepsilon \mathrm{c}_{1}, \mathrm{c}_{2}=\varepsilon \mathrm{c}_{2}, \rho_{1}=\varepsilon \rho_{1}, \mathrm{k}_{\mathrm{n}}=\varepsilon \mathrm{k}_{\mathrm{n}}, \mathrm{f}=\varepsilon \mathrm{f},\left[\begin{array}{l}\mathrm{x}_{1} \\ \mathrm{x}_{2}\end{array}\right]=\left[\begin{array}{ll}1 & 1 \\ \mathrm{r}_{1} & \mathrm{r}_{2}\end{array}\right]\left[\begin{array}{l}\mathrm{q}_{1} \\ \mathrm{q}_{2}\end{array}\right]$.

\section{Perturbation Analysis}

In this section, the method of multiple scales is applied to obtain the second-order approximate solutions of Eqs. (3) using the following form

$$
\begin{aligned}
& \mathrm{q}_{1}(\mathrm{t}, \varepsilon)=\mathrm{q}_{11}\left(\mathrm{~T}_{0}, \mathrm{~T}_{1}, \cdots\right)+\varepsilon \mathrm{q}_{12}\left(\mathrm{~T}_{0}, \mathrm{~T}_{1},+\cdots\right)+\cdots \\
& \mathrm{q}_{2}(\mathrm{t}, \varepsilon)=\mathrm{q}_{21}\left(\mathrm{~T}_{0}, \mathrm{~T}_{1}, \cdots\right)+\varepsilon \mathrm{q}_{22}\left(\mathrm{~T}_{0}, \mathrm{~T}_{1},+\cdots\right)+\cdots \\
& \mathrm{q}_{1 \tau}=\mathrm{q}_{11 \tau}\left(\mathrm{T}_{0}-\tau, \mathrm{T}_{1}, \mathrm{~T}_{2}, \cdots\right)-\varepsilon \tau \mathrm{D}_{1} \mathrm{q}_{11 \tau}\left(\mathrm{T}_{0}-\tau, \mathrm{T}_{1}, \mathrm{~T}_{2}, \cdots\right)+\varepsilon \mathrm{D}_{1} \mathrm{q}_{12 \tau}\left(\mathrm{T}_{0}-\tau, \mathrm{T}_{1}, \mathrm{~T}_{2}, \cdots\right) \\
& +\frac{\varepsilon^{2} \tau^{2}}{2} \mathrm{D}_{1}{ }^{2} \mathrm{q}_{11 \tau}\left(\mathrm{T}_{0}-\tau, \mathrm{T}_{1}, \mathrm{~T}_{2}, \cdots\right)-\varepsilon^{2} \tau \mathrm{D}_{1} \mathrm{q}_{12 \tau}\left(\mathrm{T}_{0}-\tau, \mathrm{T}_{1}, \mathrm{~T}_{2}, \cdots\right)+\cdots \\
& \mathrm{q}_{2 \tau}=\mathrm{q}_{21 \tau}\left(\mathrm{T}_{0}-\tau, \mathrm{T}_{1}, \mathrm{~T}_{2}, \cdots\right)-\varepsilon \tau \mathrm{D}_{1} \mathrm{q}_{21 \tau}\left(\mathrm{T}_{0}-\tau, \mathrm{T}_{1}, \mathrm{~T}_{2}, \cdots\right)+\varepsilon \mathrm{D}_{1} \mathrm{q}_{22 \tau}\left(\mathrm{T}_{0}-\tau, \mathrm{T}_{1}, \mathrm{~T}_{2}, \cdots\right) \\
& +\frac{\varepsilon^{2} \tau^{2}}{2} \mathrm{D}_{1}{ }^{2} \mathrm{q}_{21 \tau}\left(\mathrm{T}_{0}-\tau, \mathrm{T}_{1}, \mathrm{~T}_{2}, \cdots\right)-\varepsilon^{2} \tau \mathrm{D}_{1} \mathrm{q}_{22 \tau}\left(\mathrm{T}_{0}-\tau, \mathrm{T}_{1}, \mathrm{~T}_{2}, \cdots\right)+\cdots
\end{aligned}
$$

Substituting Eqs. (4)-(7) into Eq. (3), and equating coefficients of like powers of $\varepsilon$ yield $\varepsilon^{0}$

$$
D_{0}^{2} q_{11}+\omega_{1}^{2} q_{11}=0
$$




$$
\begin{aligned}
& D_{0}^{2} q_{21}+\omega_{2}^{2} q_{21}=0 \\
& \varepsilon^{1}: \\
& D_{0}^{2} q_{12}+\omega_{1}^{2} q_{12}=\frac{1}{m_{1}+r_{1}^{2} m_{2}}\left\{-2\left(m_{1}+r_{1}^{2} m_{2}\right) D_{0} D_{1} q_{11}-\left[c_{1}-2 r_{1} c_{1}+r_{1}^{2}\left(c_{1}+c_{2}\right)\right] D_{0} q_{11}\right. \\
& -\left[c_{1}-r_{1} c_{1}-r_{2} c_{1}+r_{1} r_{2}\left(c_{1}+c_{2}\right)\right] D_{0} q_{21}-\left(1-r_{1}\right) k_{n}\left(q_{11}+q_{21}-r_{1} q_{11}-r_{2} q_{21}\right)^{2} \\
& \left.-\left(1-r_{1}\right) \rho_{1}\left(D_{0} q_{11 \tau}+D_{0} q_{21 \tau}\right)+r_{1} f \cos (\omega t)\right\} \\
& D_{0}^{2} q_{22}+\omega_{2}^{2} q_{22}=\frac{1}{m_{1}+r_{2}^{2} m_{2}}\left\{-2\left(m_{1}+r_{2}^{2} m_{2}\right) D_{0} D_{1} q_{21}-\left[c_{1}-r_{1} c_{1}-r_{2} c_{1}+r_{1} r_{2}\left(c_{1}+c_{2}\right)\right] D_{0} q_{11}\right. \\
& -\left[c_{1}-2 r_{2} c_{1}+r_{2}^{2}\left(c_{1}+c_{2}\right)\right] D_{0} q_{21}-\left(1-r_{2}\right) k_{n}\left(q_{11}+q_{21}-r_{1} q_{11}-r_{2} q_{21}\right)^{2} \\
& \left.-\left(1-r_{2}\right) \rho_{1}\left(D_{0} q_{11 \tau}+D_{0} q_{21 \tau}\right)+r_{2} f \cos (\omega t)\right\} \\
& \text { Where } \omega_{1}^{2}=\frac{k_{1}-2 r_{1} k_{1}+r_{1}^{2}\left(k_{1}+k_{2}\right)}{m_{1}+r_{1}^{2} m_{2}}, \omega_{2}^{2}=\frac{k_{1}-2 r_{2} k_{1}+r_{2}^{2}\left(k_{1}+k_{2}\right)}{m_{1}+r_{2}^{2} m_{2}} .
\end{aligned}
$$

The solutions of Eqs. (8) and (9) can be expressed as

$$
\begin{aligned}
& \mathrm{q}_{11}=\mathrm{A}\left(\mathrm{T}_{1}\right) \mathrm{e}^{\mathrm{i} \omega_{1} \mathrm{~T}_{0}}+\overline{\mathrm{A}}\left(\mathrm{T}_{1}\right) \mathrm{e}^{-\mathrm{i} \omega_{1} \mathrm{~T}_{0}} \\
& \mathrm{q}_{21}=\mathrm{B}\left(\mathrm{T}_{1}\right) \mathrm{e}^{\mathrm{i} \omega_{2} \mathrm{~T}_{0}}+\overline{\mathrm{B}}\left(\mathrm{T}_{1}\right) \mathrm{e}^{-\mathrm{i} \omega_{2} \mathrm{~T}_{0}}
\end{aligned}
$$

Substituting Eqs. (12)-(13) into Eqs. (10)-(11), we can obtain

$$
\begin{aligned}
& \mathrm{D}_{0}{ }^{2} \mathrm{q}_{12}+\omega_{1}{ }^{2} \mathrm{q}_{12}=\frac{1}{\mathrm{~m}_{1}+\mathrm{r}_{1}^{2} \mathrm{~m}_{2}}\left\{\mathrm{~K}_{1}+\mathrm{K}_{2} \mathrm{e}^{\mathrm{i} \omega_{1} \mathrm{~T}_{0}}+\mathrm{K}_{3} \mathrm{e}^{\mathrm{i} \omega_{2} \mathrm{~T}_{0}}+\mathrm{K}_{4} \mathrm{e}^{\mathrm{i} 2 \omega_{1} \mathrm{~T}_{0}}+\mathrm{K}_{5} \mathrm{e}^{\mathrm{i} 2 \omega_{2} \mathrm{~T}_{0}}+\mathrm{K}_{6} \mathrm{e}^{\mathrm{i}\left(\omega_{1}+\omega_{2}\right) \mathrm{T}_{0}}\right. \\
& \left.+K_{7} e^{i\left(\omega_{2}-\omega_{1}\right) T_{0}}+K_{8} e^{i \omega_{1}\left(T_{0}-\tau\right)}+K_{9} e^{i \omega_{2}\left(T_{0}-\tau\right)}+K_{10} e^{i \omega T_{0}}\right\}+c c \\
& \mathrm{D}_{0}{ }^{2} \mathrm{q}_{22}+\omega_{2}{ }^{2} \mathrm{q}_{22}=\frac{1}{\mathrm{~m}_{1}+\mathrm{r}_{2}^{2} \mathrm{~m}_{2}}\left\{\mathrm{~K}_{11}+\mathrm{K}_{12} \mathrm{e}^{\mathrm{i} \omega_{1} \mathrm{~T}_{0}}+\mathrm{K}_{13} \mathrm{e}^{\mathrm{i} \omega_{2} \mathrm{~T}_{0}}+\mathrm{K}_{14} \mathrm{e}^{\mathrm{i} 2 \omega_{1} \mathrm{~T}_{0}}+\mathrm{K}_{15} \mathrm{e}^{\mathrm{i} 2 \omega_{2} \mathrm{~T}_{0}}+\mathrm{K}_{16} \mathrm{e}^{\mathrm{i}\left(\omega_{1}+\omega_{2}\right) \mathrm{T}_{0}}\right. \\
& \left.+K_{17} e^{i\left(\omega_{2}-\omega_{1}\right) T_{0}}+K_{18} e^{i \omega_{1}\left(T_{0}-\tau\right)}+K_{19} e^{i \omega_{2}\left(T_{0}-\tau\right)}+K_{20} e^{i \omega T_{0}}\right\}+c c
\end{aligned}
$$

Where cc denotes the complex conjugate terms, and $\mathrm{k}_{1}-\mathrm{k}_{20}$ are the coefficients, the express of $\mathrm{k}_{1}-\mathrm{k}_{20}$ is omitted due to space limitations.

In the following section, a case of primary resonance and 1:2 internal resonance is considered. To describe the nearness of the external resonance quantitatively, a detuning parameter $\sigma_{1}$ is introduced as $\omega=\omega_{1}+\varepsilon \sigma_{1}$. Similarly, the nearness of the internal resonance is represented by a detuning parameter $\sigma_{2}$ defined as $\omega_{2}=2 \omega_{1}+\varepsilon \sigma_{2}$. Setting the coefficients of the secular terms to zero into Eqs. (14)-(15), and yield the solvability conditions which are given by 


$$
\begin{aligned}
& \mathrm{D}_{1} \mathrm{~A}=\frac{1}{2\left(\mathrm{~m}_{1}+\mathrm{r}_{1}^{2} \mathrm{~m}_{2}\right) \omega_{1}}\left\{-\left[\mathrm{c}_{1}-2 \mathrm{r}_{1} \mathrm{c}_{1}+\mathrm{r}_{1}^{2}\left(\mathrm{c}_{1}+\mathrm{c}_{2}\right)\right] \omega_{1} \mathrm{~A}+\mathrm{i} 2\left(1-\mathrm{r}_{1}\right) \mathrm{k}_{\mathrm{n}}\left(1-\mathrm{r}_{1}-\mathrm{r}_{2}+\mathrm{r}_{1} \mathrm{r}_{2}\right) \overline{\mathrm{A} B \mathrm{~B}^{\mathrm{i} \sigma_{2} \mathrm{~T}_{1}}}\right. \\
& \left.-\left(1-\mathrm{r}_{1}\right) \rho_{1} \omega_{1} \mathrm{Ae}^{-\mathrm{i} \omega_{1} \tau}-\mathrm{i} \frac{1}{2} \mathrm{r}_{1} \mathrm{fe}^{\mathrm{i} \sigma_{1} \mathrm{~T}_{1}}\right\} \\
& \mathrm{D}_{1} \mathrm{~B}=\frac{1}{2\left(\mathrm{~m}_{1}+\mathrm{r}_{2}^{2} \mathrm{~m}_{2}\right) \omega_{2}}\left\{-\left[\mathrm{c}_{1}-2 \mathrm{r}_{2} \mathrm{c}_{1}+\mathrm{r}_{2}^{2}\left(\mathrm{c}_{1}+\mathrm{c}_{2}\right)\right] \omega_{2} \mathrm{~B}+\mathrm{i}\left(1-\mathrm{r}_{2}\right) \mathrm{k}_{\mathrm{n}}\left(1-\mathrm{r}_{1}\right)^{2} \mathrm{~A}^{2} \mathrm{e}^{-\mathrm{i} \sigma_{2} \mathrm{~T}_{1}}\right. \\
& \left.-\left(1-\mathrm{r}_{2}\right) \rho_{1} \omega_{2} B e^{-i \omega_{2} \tau}\right\}
\end{aligned}
$$

Introducing the polar notation $\mathrm{A}\left(\mathrm{T}_{1}\right)=\frac{1}{2} \mathrm{a}\left(\mathrm{T}_{1}\right) \mathrm{e}^{\mathrm{i} \theta_{1}\left(\mathrm{~T}_{1}\right)}$ and $\mathrm{B}\left(\mathrm{T}_{1}\right)=\frac{1}{2} \mathrm{~b}\left(\mathrm{~T}_{1}\right) \mathrm{e}^{\mathrm{i} \theta_{2}\left(\mathrm{~T}_{1}\right)}$ into Eqs. (16)-(17) and setting the coefficients of the real and imaginary parts to zero yield the algebraic equations as

$$
\begin{aligned}
& \mathrm{a}^{\prime}=\frac{1}{2\left(\mathrm{~m}_{1}+\mathrm{r}_{1}^{2} \mathrm{~m}_{2}\right) \omega_{1}}\left\{-\left[\mathrm{c}_{1}-2 \mathrm{r}_{1} \mathrm{c}_{1}+\mathrm{r}_{1}^{2}\left(\mathrm{c}_{1}+\mathrm{c}_{2}\right)\right] \omega_{1} \mathrm{a}\right. \\
& \left.+\left(1-\mathrm{r}_{1}\right) \mathrm{k}_{\mathrm{n}}\left(1-\mathrm{r}_{1}-\mathrm{r}_{2}+\mathrm{r}_{1} \mathrm{r}_{2}\right) \mathrm{ab} \sin \phi_{2}-\left(1-\mathrm{r}_{1}\right) \rho_{1} \omega_{1} \mathrm{a} \cos \left(\omega_{1} \tau\right)+\mathrm{r}_{1} \mathrm{f} \sin \phi_{1}\right\} \\
& \mathrm{a} \phi_{1}^{\prime}=\frac{1}{2\left(\mathrm{~m}_{1}+\mathrm{r}_{1}^{2} \mathrm{~m}_{2}\right) \omega_{1}}\left\{2\left(\mathrm{~m}_{1}+\mathrm{r}_{1}^{2} \mathrm{~m}_{2}\right) \omega_{1} \mathrm{a} \sigma_{1}\right. \\
& \left.-\left(1-r_{1}\right) k_{n}\left(1-r_{1}-r_{2}+r_{1} r_{2}\right) a b \cos \phi_{2}-\left(1-r_{1}\right) \rho_{1} \omega_{1} a \sin \left(\omega_{1} \tau\right)+r_{1} f \cos \phi_{1}\right\} \\
& \mathrm{b}^{\prime}=\frac{1}{2\left(\mathrm{~m}_{1}+\mathrm{r}_{2}^{2} \mathrm{~m}_{2}\right) \omega_{2}}\left\{-\left[\mathrm{c}_{1}-2 \mathrm{r}_{2} \mathrm{c}_{1}+\mathrm{r}_{2}^{2}\left(\mathrm{c}_{1}+\mathrm{c}_{2}\right)\right] \omega_{2} \mathrm{~b}\right. \\
& \left.-\frac{1}{2}\left(1-r_{2}\right) k_{n}\left(1-r_{1}\right)^{2} a^{2} \sin \phi_{2}-\left(1-r_{2}\right) \rho_{1} \omega_{2} b \cos \left(\omega_{2} \tau\right)\right\} \\
& \mathrm{b}\left(2 \phi_{1}^{\prime}+\phi_{2}^{\prime}\right)=\frac{1}{2\left(\mathrm{~m}_{1}+\mathrm{r}_{2}^{2} \mathrm{~m}_{2}\right) \omega_{2}}\left\{2\left(\mathrm{~m}_{1}+\mathrm{r}_{2}^{2} \mathrm{~m}_{2}\right) \omega_{2} \mathrm{~b}\left(2 \sigma_{1}-\sigma_{2}\right)\right. \\
& \left.-\frac{1}{2}\left(1-r_{2}\right) k_{n}\left(1-r_{1}\right)^{2} a^{2} \cos \phi_{2}-\left(1-r_{2}\right) \rho_{1} \omega_{2} b \sin \left(\omega_{2} \tau\right)\right\}
\end{aligned}
$$

Where $a$ and $b$ are the amplitude of the first and second mode, $\phi_{1}=\sigma_{1} T_{1}-\theta_{1}, \phi_{2}=2 \theta_{1}-\theta_{2}-\sigma_{2} T_{1}$. The response of the absorber and primary system can be approximately express as follow: $x_{1} \approx a \cos \left[\omega_{1} T_{0}+\theta_{1}\left(T_{1}\right)\right]+b \cos \left[\omega_{2} T_{0}+\theta_{2}\left(T_{1}\right)\right], x_{2} \approx r_{1} a \cos \left[\omega_{1} T_{0}+\theta_{1}\left(T_{1}\right)\right]+r_{2} b \cos \left[\omega_{2} T_{0}+\theta_{2}\left(T_{1}\right)\right]$.

\section{The Amplitude - Frequency Response Curves of Linear Vibration System}

The equilibrium solutions can be obtained by setting $a^{\prime}=\phi_{1}^{\prime}=b=\phi_{2}^{\prime}$ in Eqs. (18)-(21). Fig. 2 shows the amplitude-frequency response curves of the linear vibration system. The parameters are chosen as follows: 
$\mathrm{m}_{1}=255 \mathrm{~kg} \quad, \quad \mathrm{~m}_{2}=1600 \mathrm{~kg} \quad, \quad \mathrm{k}_{1}=130128 \mathrm{~N} / \mathrm{m} \quad, \quad \mathrm{k}_{2}=3135000 \mathrm{~N} / \mathrm{m} \quad$, $\mathrm{k}_{\mathrm{n}}=13012.8 \mathrm{~N} / \mathrm{m}, \mathrm{c}_{1}=2000 \mathrm{~N} \cdot \mathrm{s} / \mathrm{m}, \mathrm{c}_{2}=13000 \mathrm{~N} \cdot \mathrm{s} / \mathrm{m}, \omega_{1}=21.9 \mathrm{rad} / \mathrm{s}, \omega_{2}=43.2 \mathrm{rad} / \mathrm{s}$, $\sigma_{2}=-0.6$. In the following figures, amp1 and amp2 represent the primary system and isolation system.

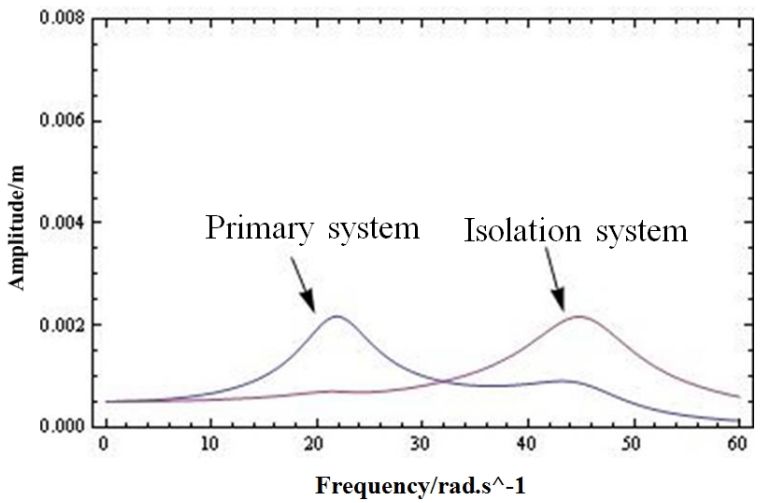

Fig. 2: Amplitude-frequency response curves of the linear vibration system.

It can be observed from Fig. 2, the amplitude of the primary system is about $2.2 \mathrm{~mm}$ when the external excitation frequency nears the first modal frequency of the vibrating system. The amplitude of the isolation system is maximum when the external excitation frequency nears the second modal frequency of the vibrating system. In the next section, we discuss the effect of delayed feedback control on vibration suppression of the vibrating system.

\section{Vibration Suppression of the Delayed Feedback Control}

From the above section, it can be observed that the amplitude of the primary system is maximum, we take $\sigma_{1}=0$ and $\sigma_{1}=0.3$ as examples to discuss the delayed feedback control on vibration suppression of the system.

The amplitude-delay response curves of the primary system and isolation system for different values of the delayed feedback gain are shown in Fig. 3-Fig. 5 when $\sigma_{1}=0$, where the other parameters are: $\mathrm{m}_{1}=255 \mathrm{~kg} \quad, \quad \mathrm{~m}_{2}=1600 \mathrm{~kg} \quad, \quad \mathrm{k}_{1}=130128 \mathrm{~N} / \mathrm{m} \quad, \quad \mathrm{k}_{2}=3135000 \mathrm{~N} / \mathrm{m} \quad$, $\mathrm{k}_{\mathrm{n}}=13012.8 \mathrm{~N} / \mathrm{m}, \mathrm{c}_{1}=2000 \mathrm{~N} \cdot \mathrm{s} / \mathrm{m}, \mathrm{c}_{2}=13000 \mathrm{~N} \cdot \mathrm{s} / \mathrm{m}$. Amp1 represents the amplitude of the primary system, amp2 represents the amplitude of the isolation system.

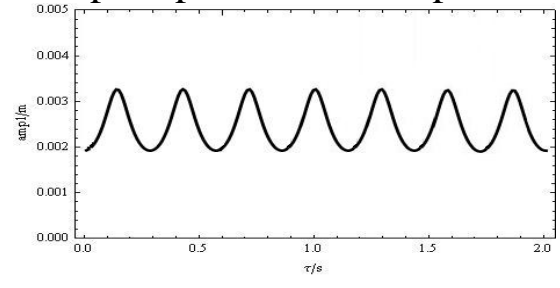

(a)

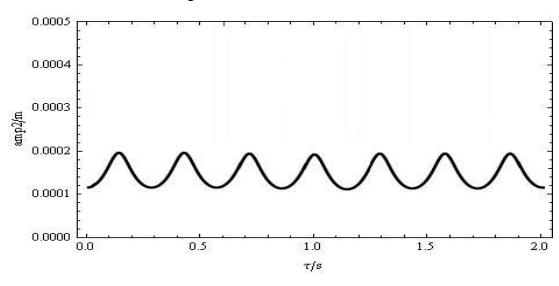

(b)

Fig. 3: Amplitude-delay response curves when $\rho_{1}=500$, (a) primary system, (b) isolation system

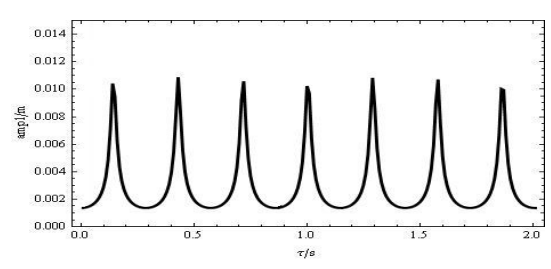

(a)

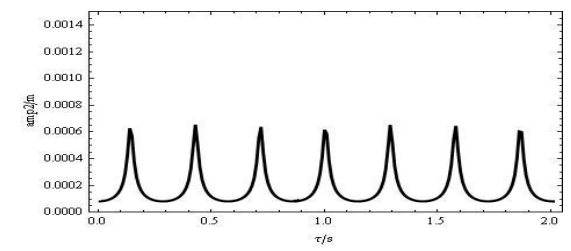

(b)

Fig. 4: Amplitude-delay response curves when $\rho_{1}=1500$, (a) primary system, (b) isolation system 


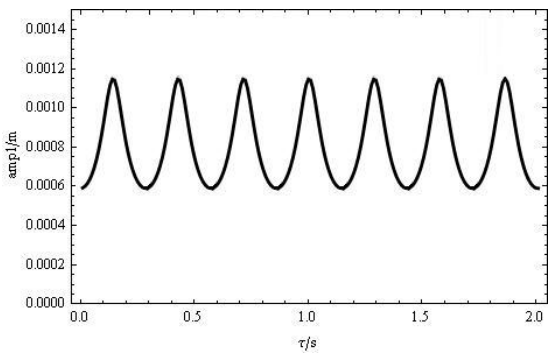

(a)

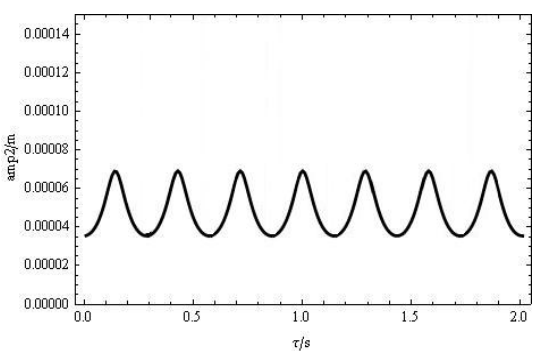

(b)

Fig. 5: Amplitude-delay response curves when $\rho_{1}=6000$, (a) primary system, (b) isolation system

Fig. 3 shows the amplitude-delay response curves of the primary system and isolation system when $\rho_{1}=500$. As $\tau$ increases, the amplitude of the primary system increases in the beginning. Then the amplitude of the primary system decreases as $\tau$ increases. It can be observed that there are some interval for time delay the amplitude of the primary system can be suppressed to a minimum value (about $1.90 \mathrm{~mm}$ ). These time delay interval we called it "time delay vibration suppression interval".

As the gain increases to $\rho_{1}=1500$, Fig. 4 shows that the amplitude of the primary system can be suppressed to a minimum value (about $1.30 \mathrm{~mm}$ ) when time delay is located in "time delay vibration suppression interval". It can be observed the amplitude of the primary system can be suppressed to a smaller value (about $0.58 \mathrm{~mm}$ ) in Fig. 5 comparing with Fig. 4.

The amplitude-delay response curves of the primary system and isolation system for different values of the delayed feedback gain are shown in Fig. 6-Fig. 8 when $\sigma_{1}=0.3$, where the other parameters are: $\mathrm{m}_{1}=255 \mathrm{~kg} \quad, \quad \mathrm{~m}_{2}=1600 \mathrm{~kg} \quad, \quad \mathrm{k}_{1}=130128 \mathrm{~N} / \mathrm{m} \quad, \quad \mathrm{k}_{2}=3135000 \mathrm{~N} / \mathrm{m} \quad$, $\mathrm{k}_{\mathrm{n}}=13012.8 \mathrm{~N} / \mathrm{m}, \mathrm{c}_{1}=2000 \mathrm{~N} \cdot \mathrm{s} / \mathrm{m}, \mathrm{c}_{2}=13000 \mathrm{~N} \cdot \mathrm{s} / \mathrm{m}$. Amp1 represents the amplitude of the primary system, amp 2 represents the amplitude of the isolation system.

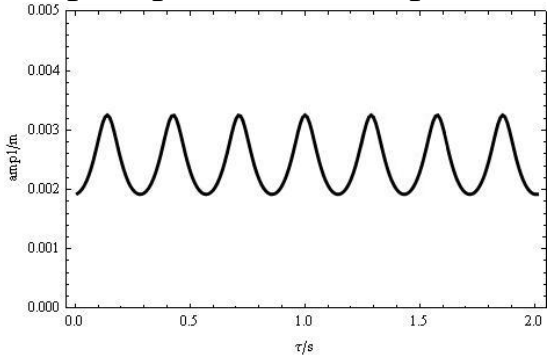

(a)

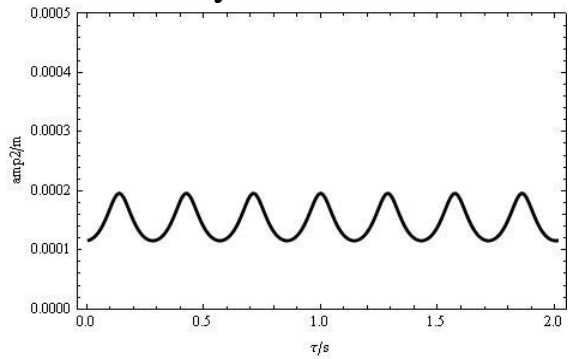

(b)

Fig. 6: Amplitude-delay response curves when $\rho_{1}=500$, (a) primary system, (b) isolation system

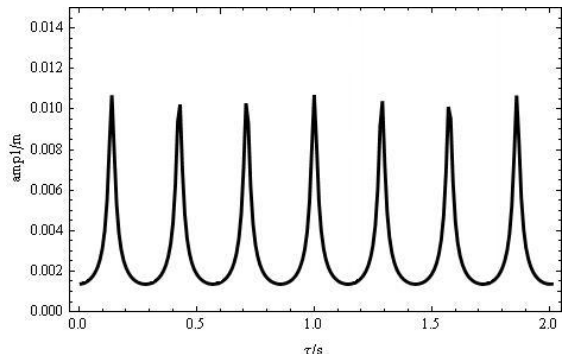

(a)

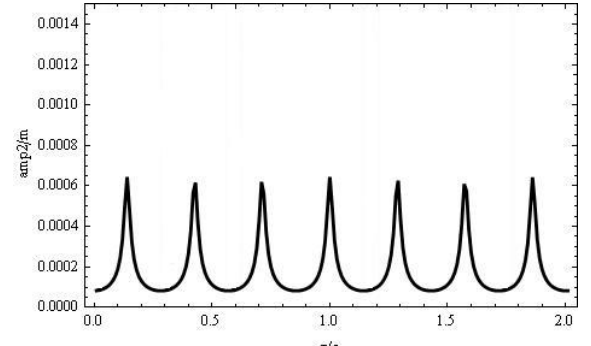

(b)

Fig. 7: Amplitude-delay response curves when $\rho_{1}=1500$, (a) primary system, (b) isolation system 


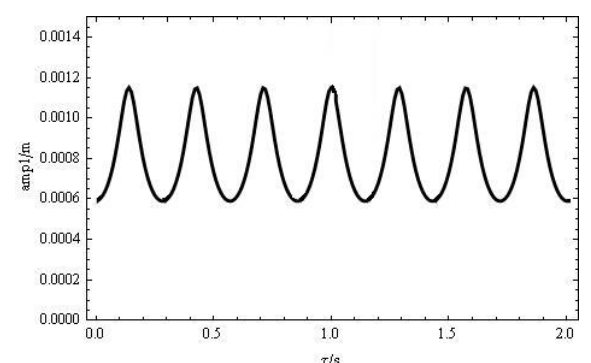

(a)

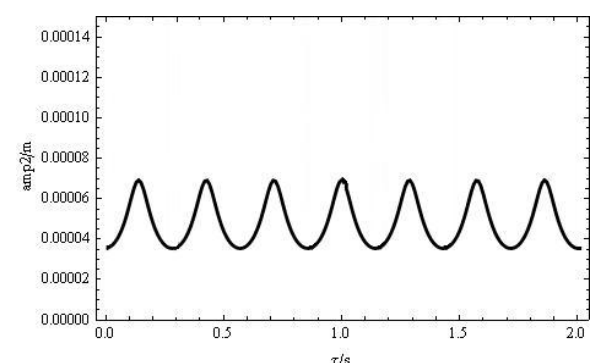

(b)

Fig. 8: Amplitude-delay response curves when $\rho_{1}=6000$, (a) primary system, (b) isolation system

In Fig. 6, It can be observed that when time delay is located in "time delay vibration suppression interval", the amplitude of the primary system can be suppressed to a minimum value (about $1.94 \mathrm{~mm}$ ). As the gain increases to $\rho_{1}=1500$, Fig. 7 shows that the amplitude of the primary system can be suppressed to a minimum value (about $1.30 \mathrm{~mm}$ ) when time delay is located in "time delay vibration suppression interval". It can be observed the amplitude of the primary system can be suppressed to a smaller value (about $0.59 \mathrm{~mm}$ ) in Fig. 8 comparing with Fig. 7.

\section{Summary}

The delayed feedback control is applied to control the vibration in tracked emergency ambulance when the external excitation frequency nears the first modal frequency of the vibrating system. The effect of the gain and time delay on vibration suppression of the primary system is studied. The amplitude of the primary system can be suppressed when the appropriate gain and time delay are chosen. There are some time delay vibration suppression intervals for a fixed gain, the amplitude of the primary system can be suppressed to a minimum when time delay located in these time delay interval. As the gain increase, the performance vibration suppression is improved when the time delay located in the time delay vibration suppression interval.

\section{Acknowledgement}

This research was financially supported by the National Natural Science Foundation of China No. 11372125.

\section{References}

[1] M. Yang, X.X. Xu, C. Su, F.S. Li, S. Bai, S.L. Tan. Vibration characteristics and motion stability of a tracked ambulance nonlinear vibration-reduction system. Journal of Vibration and Shock. 32 (2013) 183-188.

[2] X.X. Xu, M. Wang, X.D.Cui. Simulation analysis and optimization design for vibration damping of stretchers on emergency ambulance. Journal of Vibration Engineering. 22 (2009) 352-356.

[3] M. Yang, X.X. Xu, S.L. Tan, S. Bai, C. F.S. Li. Parameter identification and optimization of design of tracked ambulance two-degree damping system. Machinery Design and Manufacture. 4 (2013) 42-46.

[4] N. Olgac, B.T. Holm-Hansen. A novel active vibration absorption technique: delayed resonator. Journal of Sound and Vibration. 176 (1996) 93-104.

[5] Y.Y. Zhao, J. Xu. Using the delayed feedback control and saturation control to suppress the vibration of the dynamical system. Nonlinear Dynamics. 67 (2012) 735-753.

[6] Y.Y. Zhao, J. Xu, Effects of delayed feedback control on nonlinear vibration absorber system, Journal of Sound and Vibration 308(2007) 212-230. 